\title{
Leader
}

\section{Legal and ethical aspects of the vegetative state}

\author{
Sheila A M McLean
}

\begin{abstract}
The diagnosis of persistent or permanent vegetative state (PVS) raises ethical and legal problems. Strict adherence to the doctrine of the sanctity of life would require carers to continue to maintain the individual, perhaps for many years. However, few would regard this as an appropriate outcome when the person clearly has no capacity to interact with the environment and has no likelihood of recovery. However, the ethical and legal commitment to the sanctity of life has led courts to employ a variety of approaches to this situation in order to find a way in which the person in PVS can be allowed to die. It is argued that each of the approaches is disingenuous and ultimately unhelpful. What the law is doing is endorsing non-voluntary euthanasia, but dressing it up as something else. This is unhelpful for all concerned and the time has come for a review of all end of life decisions so that doctors, patients, and relatives can make honest decisions without fear of legal reprisal.
\end{abstract}

Keywords: persistent vegetative state; ethics; law

Since Jennett and Plum first identified the condition known as persistent vegetative state (PVS), ${ }^{1}$ it has been one of the most ethically troubling of diagnoses. While undoubtedly a clinical breakthrough in diagnostic terms, numerous questions have been raised, ranging from much publicised doubts about its accuracy, to the ethics of dealing with people so diagnosed, to the response which the law can or should make to people in this condition. To an extent, although admittedly this is not unarguable, the clinical problems associated with this diagnosis have been effectively managed-not least by the clinical guidance given concerning when the condition should be diagnosed. ${ }^{2}$ In addition, the distinction now drawn between vegetative state and permanent (not persistent)

Department of Medical Ethics, University of Glasgow, Glasgow G12 8QQ, UK S A M McLean

Correspondence to: Professor McLean.

Accepted for publication 5 November 1998 "After acute insults patients may recover to varying degrees after being vegetative for some weeks, and occasionally after several months. Children more frequently recover than adults, and traumatic cases recover more often that non-traumatic. Many medical authorities have declared that the vegetative state can be considered permanent (as distinct from persistent) after one year, and several consider that an earlier decision can be made in non-traumatic cases." ${ }^{3}$ vegetative state may have served to alleviate some of the fears of the public, whipped up very often in the media, concerning reported incidences of people recovering from PVS. ${ }^{a}$

There can be no doubt that accuracy of diagnosis is of particular importance in this condition, since its consequences are potentially so serious for the individuals concerned and for their families and carers. In this sense, the diagnosis stands virtually alone in medicine. Following most clinical diagnoses, the issues to be addressed by the clinician (and the patient where conscious) concern the management of disease. Whether or not a person accepts or rejects recommended treatment, whether or not treatment is available, and whether or not treatment should be offered are all decisions of great moral import. However, in the case of the patient in permanent vegetative state, the dilemmas confronted are arguably of much greater moral and ethical weight, and much more closely allied to legal matters.

More than any other diagnosis, PVS pushes into the forefront of concern matters concerning quality of life, and forces carers and families to address the question of whether or not the individual - who is alive for both clinical and legal purposes - should be kept alive or helped/ allowed to die. In a society which still eschews the deliberate assisting of someone to die even when their condition is hopeless, the PVS patient presents an uncomfortable problem. In general, those who are alive - and who do not have a life threatening condition-can and do expect that doctors and nurses will make every effort to maintain that life. And in fact this is precisely what will generally happen. The biggest problem in routine circumstances is less concerned with the question of providing treatment but rather the fact that some patients may refuse it. The fact that patients have the right to refuse life preserving treatment (in other words to choose death) is doubtless an agonising moral dilemma for their carers. On the one hand, the patient's right to refuse must be respected, while at the same time the doctor may know that the patient could be saved. This presents a clear ethical tension, although the legal position is absolutely clear. ${ }^{4}$

However, when the patient is in a permanent

vegetative state the parameters shift considerably, not least because the patient cannot consent to or refuse the intervention which is keeping them alive. While still adhering to the 
principle of the sanctity of life, there are intelligible reasons why carers might wish to see a peaceful end to a life which is irrevocably bereft of quality-even consciousness. Of course, for some, such decisions are anathema-the person is alive and therefore that life should be preserved. It is not, on this view, for us to "play God," and any removal of sustenance which would lead to death is completely unacceptable - both unethical and unlawful. However, for others (possibly the majority?) the resolution of the dilemma presented by the patient in PVS is less clear cut. For whatever reasons (and there may be many) it appears that increasingly the strict adherence to the sanctity of life in these situations is seen as unsatisfactory. Rather, a more gradualist approach to the ethics of the situation is taken, with pressure perhaps coming from family and health care workers to release the person from the prison which is PVS.

Several points need to be made, however, and their significance should not be underestimated. Starkly put, the person in PVS is alive, being sustained usually by the assisted provision of nutrition and hydration. With such assistance, they may live for many years; without it they will undoubtedly perish. Strict adherence to the principle of the sanctity of life would take no account of the quality of that life - simply, it should be maintained, particularly when the means to sustain it (which may also include the occasional use of antibiotics, for example) can scarcely be described as extraordinary medical treatment. But increasingly, we can witness a move away from such strict adherence to that principle. Although courts (and others) will generally maintain that this is the cornerstone of our society, ${ }^{b}$ they seem prepared to engage in justifying deviations from the principle on grounds which, for some, are at best disingenuous. In fact, the PVS patient raises acutely the attitude of the whole community to end of life decisions, although this is generally ignored or obfuscated by seeking to present a different picture, namely that their position is so singular that decisions which bring about their death are ethically and legally distinguishable from assisting death in other circumstances.

However, in the context of this article, it will be argued that the PVS patient is, when nutrition and hydration are removed, a classic case of non-voluntary euthanasia. It will further be argued that the rest of the debate concerning end of life decisions can be richly informed by the tragic situation of those who suffer from this condition. Before continuing, it is worth explaining my terminology. Taking the description used by Glover, ${ }^{6}$ there are three categories of euthanasia: voluntary (where the person is

\footnotetext{
${ }^{b}$ Belief in the special worth of human life is at the heart of civilised society. It is the fundamental value on which all others are based, and is the foundation of both law and medical practice. The intentional taking of human life is therefore the offence which society condemns most strongly." 5 This view can be contrasted with the words of Lord Mustill in the case of Airedale NHS Trust $v$ Bland [1993] 1 All ER 821, at p 891: “The interest of the state in preserving the lives of its citizens is very strong, but it is not absolute."
}

assisted to die in their best interests after a competent request), non-voluntary (where are person is assisted to die in their best interests but without being able to make such a request), and involuntary (where a person is assisted to die, supposedly in their best interests, but against their expressed wishes). The last of these, which can scarcely be distinguished from murder, is of no concern here.

Although apparently the most clear cut (ethically speaking), the first of these is also of no concern because for the present it remains outlawed. ${ }^{c}$ But the second category - that of non-voluntary euthanasia-is of importance here as it most clearly describes what would happen were nutrition and hydration to be removed from someone in PVS. There are, of course, some objections to this analysis and it is worth exploring them.

It is useful to do this by reference to the two main cases which have reached the courts in the United Kingdom. The first of these was the case of Airedale NHS Trust $v$ Bland $^{7}$ and the second, Law Hospital NHS Trust $v$ Lord Advocate and others. ${ }^{8}$ Although there were subtle differences in emphasis in these cases, based perhaps on the different legal traditions of England and Scotland, in essence the conclusion was the same, and for this reason (plus the fact that the Bland case reached the House of Lords, the supreme civil court of the United Kingdom) the Bland judgement will form the basis of the discussion.

On my analysis, the court's authorisation of the removal of nasogastric feeding/hydration from Anthony Bland amounted to the endorsement of non-voluntary euthanasia. Since this is likely to be an uncomfortable conclusion, it is necessary to look at the arguments against it, some of which were endorsed by the House of Lords.

The first, and major, objection would be that the removal of nutrition/hydration is an omission and not an act. Since we are generally held culpable for our acts but not for our omissions, then legally at least there should be no objection to their removal, and it most certainly does not involve the taking of a life, a characteristic which is central to euthanasia. Of course, this begs the ethical question, since law and morality need not always equate. The ethical question would concern itself with the morality of contriving the end of an otherwise sustainable life, and would have little regard for the legal position concerning culpability for acts and omissions. Hence, where the doctrine of double effect is used as a successful moral defence, ${ }^{d}$ it is the intention of the doctor which is held to shape the quality of the act. Thus providing potentially lethal doses of analgesia is permitted where the intention is to alleviate pain, even if it is reasonably foreseeable that

${ }^{c}$ Voluntary euthanasia and assisted suicide are tolerated in The Netherlands under strict controls agreed by the law and the Dutch Medical Association. In the USA the voters of the state of Oregon last year re-endorsed the terms of the Death With Dignity Act 1994, which permits physician assisted suicide in some restricted circumstances. Some 10 people have sought to use the legislation since November 1997. 
death will ensue as a direct result of the analgesia. What the doctor intends is the relief of pain; what they do not intend is death. However, evidently in the case of the patient in PVS, death is the intended outcome, yet courts have shown themselves willing to permit this. This they have done on various grounds.

First, by making the distinction between an act and an omission it has been held not unlawful to withdraw nutrition/hydration on the basis that this is in fact an omission, not an act. ${ }^{9}$ Clearly, this could be described as somewhat disingenuous, but taking it at face value doesn't alleviate the dilemma. It is generally, as has been said, the case that omissions are not necessarily culpable, but the fact remains that they are culpable where there is a pre-existing duty of care between the parties. Thus I may have no obligation to the person in PVS not to omit to provide the means for survival, but those who are in a legal relationship-for example doctors-undoubtedly do in strict legal terms have just such an obligation. Thus, legally at least, there is an obligation not to omit to provide nourishment.

Second, it was argued by some judges in the Bland case that the provision of nourishment is a medical decision, as nutrition/hydration are medical treatments. ${ }^{e}$ Clearly this is a highly arguable position, since it might be thought that nourishment is a basic of life rather than a medical matter. For some, however, the fact that it is provided artificially is sufficient to make a distinction. For example, breathing is an essential of life, but doctors are not therefore obliged to place every person who is not breathing on a ventilator, nor to keep them on it when continued treatment is futile and the person has lost the capacity to breathe spontaneously. Moreover, some would argue that since it is those with clinical skills who establish the nasogastric feeding, then this makes it even more clearly a medical matter. This, of course, also begs a question, since presumably nonmedical personnel could be trained to do this. Therefore, describing it as "medical treatment" may seem a little far fetched, at least in these terms. Moreover, the people who have lost the capacity to eat for themselves are not necessarily in the same position as people who have lost the capacity to breathe.

A third route referred to "best interests." $f$ Briefly, this is a test favoured by the United Kingdom courts when dealing with those who cannot speak for themselves. ${ }^{g}$ In these cases,

${ }^{d}$ Briefly, this doctrine holds that a "bad" outcome (for example, death) is not morally culpable if it is brought about by a "good" act (for example, the provision of analgesia) so long as the bad outcome was not intended, even if it was foreseen. This was given legal endorsement in the case of $\mathrm{R} v$ Adams [1957] Crim. LR 365.

${ }^{e}$ Lord Goff: "There is overwhelming evidence that, in the medical profession, artificial feeding is regarded as a form of medical treatment; and even if it is not strictly medical treatment, it must form part of the medical care of the patient." ${ }^{\prime 10}$ In the same case, Lord Mustill (at p 995) seems less sanguine about accepting this, considering that the issues raised are much wider than the medical and concluding that, "...it may be said that the decision is ethical, not medical, and that there is not reason in logic why on such a decision the opinions of doctors should be decisive.” third parties may be empowered to act (or omit to act) when it is thought that the person who is incapacitated would have their best interests served by the act or omission. However, this is a peculiarly difficult test to satisfy in most cases. It is very often a matter of little more than personal judgement whether or not the test is met, yet it can have consequences which, in some cases, may prove fatal for the person whose interests are being assessed. However, it is even more difficult to apply this test in the case of a person in PVS. By the nature of the diagnosis, such a person has no interests whatsoever (or at least no contemporaneous interests), far less any "best" interests. Thus, perhaps inevitably in the absence of an advance statement from the person concerned, ${ }^{h}$ the interests being served are at best speculative and at worst actually the interests of others.

A brief exposition of the arguments and counter arguments shows just how complex is the situation when dealing with the patient in PVS - particularly when those who seek to end the patient's life also wish to celebrate the overarching importance of the sanctity of life principle. Common sense, among other things, makes it evident that the patient is in fact being helped to die, yet our aversion to recognising this fact means that the law (and those who seek to use it) have had to engage in a kind of sophistry which can scarcely leave any of them feeling entirely comfortable. In addition, the avoidance of the main issue permits rather than prevents the generation of a slippery slope. This last form of argument would say that once you permit $A$, then $B$ (and perhaps $C$ ), which is less desirable, will inevitably be permitted also. This is often a poor argument, ${ }^{i}$ but in this case we can see that it may work. If $\mathrm{A}$ is allowed, but the grounds on which it is allowed are disingenuous or poorly reasoned, then it is very much easier to permit B (and perhaps C). Without a solid basis for drawing boundaries, it is all too simple to shift the goal posts. Already, in one Irish case, we have seen that a person who was described as being nearly in PVS has had nutrition/hydration removed with the authority of the court.

In the Bland case, at least two of the judges expressed themselves as being deeply con-

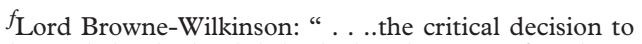
be made is whether it is in the best interests of Anthony Bland to continue the invasive medical care involved in artificial feeding." ${ }^{11}$

${ }^{g}$ As Lord Goff notes: other jurisdictions favour other tests such as "substituted judgement," but he does not consider " . ...that any such test forms part of English law in relation to incompetent adults ...,1

hord Keith: "...it is unlawful, so as to constitute both a tort and the crime of battery, to administer medical treatment to an adult, who is conscious and of sound mind, without his consent .... This extends to the situation where the person, in anticipation of his, through one cause or another, entering into a condition such as PVS, gives clear instructions that in such event he is not to be given medical care, including artificial feeding, designed to keep him alive."13

${ }^{i}$ Dworkin R: “. . . .slippery slope arguments . . . are very weak ones. They seeming only disguises for deeper convictions that actually move most opponents of [in this case] euthanasia." ${ }^{14}$

J"I have no doubt that it is for Parliament, not the courts, to decide the broader issues which this case raises." $^{15}$ 
cerned about the arguments used to justify the outcome. Lord Browne-Wilkinson in particular called for statutory intervention as the only way that doctors, families, and patients could be clear and consistent in these most tragic decisions. ${ }^{j}$ Lord Mustill, in summarily dismissing the use of acts and omissions as a morally sound device to authorise removal of the nutrition/hydration, ${ }^{k}$ expressed himself as being deeply troubled by the facts of the case. In the Law Hospital case, the Lord President, Lord Hope, introduced the concept of "benefit" $m$ to reach the conclusion that the withdrawal of nourishment need not be unlawful. Arguably, however, this is only a recasting of the "best interests" test which has already been criticised.

So where does this lead us? As was said at the beginning of this brief article, the diagnosis of PVS - even assuming its accuracy-poses an unusually complex set of dilemmas. With the exception of those whose moral perspective would demand the preservation of all life no matter how lacking in quality, the ethical and legal position is clouded. The end of the patient's life may seem to be the best outcome, but there are real difficulties in finding an ethically satisfactory route to permitting the patient to die. In large part this is, as has been suggested, because carers and courts alike seem reluctant to accept that the intention is to ensure death. To do so would be to drive a coach and horses through the repeated appeals to the sanctity of life doctrine as the bedrock of decisions in such cases. Yet trying to avoid this issue leads to ethical and legal sophistry and leaves all of those concerned in a situation of moral uncertainty.

This can only be an unsatisfactory conclusion. But it is not insoluble, although the route to its resolution is not easy. Two avenues present themselves. The first would accept that in the absence of a sound ethical basis, such decisions should never be taken. Thus all available assistance should be given to those in PVS and their lives should be maintained no matter the quality of those lives. This has a simplicity

$k$ "The conclusion that the declarations can be upheld depends crucially on a distinction drawn by the criminal law between acts and omissions ....The acute unease which I feel about adopting this way through the legal and ethical mazes .....is due in large part to the sensation that however much the terminologies may differ the ethical status of the two courses of action is for all relevant purposes indistinguishable." 16

" "....I must admit to having felt profound misgivings about almost every aspect of this case."1

${ }^{m}$ The question posed was whether or not judging what was in the "best interests" of the patient might not be helpfully informed by addressing whether or not continued treatment could be said to benefit the patient. about it which will appeal to many. However, it will not satisfy the instincts of many others for various reasons. First, provision of nutrition and hydration in these cases merely prolongs an existence, not a life. Second, for those who see nutrition and hydration as medical treatment in these situations, it flies in the face of accepted morality and medical practice to force doctors to continue to treat where the situation is hopeless - that is, where treatment is futile. Third, the health care team and the family will be placed under enormous stress if existence is prolonged in this way. And finally, the patient is in an undignified position, bereft of consciousness and control.

However, if this latter view is to prevail and to become established in our legal tradition, some way must be found to facilitate its application without resorting to the use of rationales which barely stand up to scrutiny. In fact, the only way to achieve this is to reassess attitudes to all end of life decisions; to accept that they are more similar than dissimilar, and to evaluate and enumerate any situations where a deviation from the general rule of the sanctity of life is permissible. ${ }^{18}$ This may at first sight seem to be a bigger task than one would wish to take on, but it may ultimately be the only way to ensure that the patient in PVS is treated compassionately, that doctors can exercise their judgement without fear of legal reprisal, and that families can achieve an outcome which, however painful, is compassionate.

1 Jennett B, Plum F. Persistent vegetative state after brain damage. Lancet 1972;i:734.

2 British Medical Association. Guidelines on treatment decisions for patients in the persistent vegetative state. In: Annual report. London: BMJ Publishing Group, 1993: appendix 7 .

3 Jennett B. Managing patients in a persistent vegetative state since 'Airedale NHS Trust $v$ Bland.' In: McLean SAM, ed. Death, dying and the law. Aldershot: Dartmouth, 1996:20.

1 All ER 819: Re T (1992) 9 BMLR 46; for a comparative view, see Malette $v$ Shulman (1990) $67 \operatorname{DLR}(4 \mathrm{th}) 321$ (Canada).

5 Report of the Select Committee on Medical Ethics (HL Paper 21). London: HMSO, 1994:13, para 34.

6 Glover J. Causing death and saving lives. Harmondsworth: Penguin, 1977 (reprinted 1984).

7 Airedale NHS Trust $v$ Bland [1993] 1 All ER 821, at p 891.

839 BMLR 166 (1998). [The case was heard in the Court of Session in 1996.]

9 Airedale NHS Trust $v$ Bland [1993] 1 All ER 821, at pp 868-9. [For a different perspective, see Lord Mustill in the same case at $\mathrm{p}$ 884.]

10 Airedale NHS Trust $v$ Bland [1993] 1 All ER 821, p 871.

11 Airedale NHS Trust $v$ Bland [1993] 1 All ER 821, 883.

12 Airedale NHS Trust $v$ Bland [1993] 1 All ER 821, p 872.

13 Airedale NHS Trust $v$ Bland [1993] 1 All ER 821, p 860.

4 Dworkin R. When is it right to die? New York Times, May 5, 1994.

15 Airedale NHS Trust $v$ Bland [1993] 1 All ER 821, p 878.

16 Airedale NHS Trust $v$ Bland [1993] 1 All ER 821, p 885.

17 Airedale NHS Trust $v$ Bland [1993] 1 All ER 821, p 898.

18 McLean SAM. Law at the end of life-what next? In: McLean SAM, ed. Death, dying and the law. Aldershot: Dartmouth, 1996. 